\title{
Fabrication of Closed-Cell Magnesium Composite Foam with Fine and High Roundness Pore Structure
}

\author{
Email address: \\ wmzhao@hebut.edu.cn (Weimin Zhao) \\ ${ }^{*}$ Corresponding author \\ ${ }^{\dagger}$ Nannan Wang and Jing Wang are co-first authors.
}

Nannan Wang ${ }^{\dagger}$, Jing Wang ${ }^{\dagger}$, Xingchuan Xia, Weimin Zhao*

School of Materials Science and Engineering, Hebei University of Technology, Tianjin, PR China

\section{To cite this article:}

Nannan Wang, Jing Wang, Xingchuan Xia, Weimin Zhao. Fabrication of Closed-Cell Magnesium Composite Foam with Fine and High Roundness Pore Structure. Science Research. Vol. 7, No. 4, 2019, pp. 51-59. doi: 10.11648/j.sr.20190704.12

Received: January 2, 2019; Accepted: January 21, 2019; Published: October 16, 2019

\begin{abstract}
Though metal foams possess excellent overall performances, its performances behave quite different due to its apparent aperture difference of pores diameter, pores roundness and significant macrostructure flaws, such as sharp edged pores and incomplete cell walls. It is meaningful to reduce macrostructure defects or improve pores structure uniformity of metal foams from the view point of practical applications. In this work, different thickening agents were added into AZ31B magnesium composite foams to balance foaming process and improve the homogeneity of pore diameter, pore roundness and cell wall integrity. The results showed that pore diameter, roundness of the pores and integrity of cell walls were obviously influenced by thickening agents. Based on a large number of experimental results, calcium granules and magnesium cerium intermediate alloy were used to control the number and morphology of solid particles in magnesium melt, and a kind of magnesium composite foams with fine roundness pores and complete cell wall structure were obtained.
\end{abstract}

Keywords: Magnesium Matrix Composite Foam, Spatial Structure, Solid Particles, Ceramic Microspheres

\section{Introduction}

Due to its low density, high strength, good noise insulation, excellent acoustic absorptivity and vibration reducing performance, closed-cell metal foams have been widely used in traffic transportation, aerospace, navigation, explosion shock absorption and noise abatement engineering fields. Moreover, owing to its higher specific strength and stiffness, magnesium alloy foams have been causing widespread concern for past decades and most of the researches were about its preparation methods, foaming stability and mechanical properties [1]. Up to date, spatial structure of magnesium alloy foams is inhomogeneous with large distribution range of pore diameters, lower pore roundness and incomplete cell walls. Inhomogeneous spatial structures and flaws deteriorate its overall performances and limit its applications as structural and functional materials [2-5]. To solve these problems, Bhogi et al. carried out a group of contrast experiments about the effect of thickening step on the foaming stabilization of $\mathrm{Al}-\mathrm{Mg}$ alloy using melt foaming method. The results showed that stabilization and foaming effect of metal foam was attributed to the formation of oxides in the melt [6]. Meanwhile, Heim et al. investigated the stabilization of aluminium foams and films by joint action of dispersed particles and oxide films, it concluded that particles and formation of an oxide skin were necessary for foam stabilization [7]. Foaming process stability was mainly because of the presence of particles, and the particles suppressed the drainage of melt through films and plateau borders which were important for the improvement of melt environment and the stability of foaming stage [8]. Braszczyńska-Malik et al. prepared magnesium composite foam by negative pressure infiltration technique using fly ash cenospheres as pore fillers, and the interface integration between magnesium matrix and fly ash cenospheres with Ni-P coating was investigated, the results showed that adding fly ash cenospheres with Ni-P coating would effectively avoid the cenospheres be penetrated, increase the porosity and finally obtain fly ash cenospheres homogeneous distribution in magnesium composite foam [9, 10]. Anbuchezhiyan et al. reported that externally-added hollow glass microspheres 
could not only improve the mechanical characters of magnesium matrix composite foam, but also slow down its corrosion rate [11]. As described above, researchers have been making effort to improve the foaming effects and reinforce the matrix of magnesium composite foam by controlling the stability of foaming process. However, there are still some defects in magnesium composite foams, such as, the roundness of pore is still low, the pore distribution is inhomogeneous, the mean pore diameter is big and part of big pores usually exist in the magnesium composite foams [12]. It is accessible that fine and high roundness pores are beneficial for the improvement of magnesium composite foams mechanical properties just like the spheroidal graphite to ductile iron, where fine and high roundness spheroidal graphite can significantly improve the mechanical properties of ductile irons [13]. Thus, it is foreseeable that magnesium composite foams with fine and high roundness pores will possess better mechanical properties [14-15].

Nowadays, among all of the routes, melt foaming method is the most commonly used route for metal matrix composite foam production due to its lower cost, higher production efficiency and larger size production [16, 17]. However, its foaming effect needs further improved from the perspective of spatial structure of the foams. In this work, hollow ceramic microspheres (CMs) were added into the AZ31B magnesium alloy produce in-situ particles. Furthermore, different kinds of thickening agents were used to evaluate their effect on the foaming stage and the final foaming effects. Also, composite thickening mechanism of $\mathrm{Ca}$ and $\mathrm{Mg}$-30Ce for fabricating of magnesium composite foam with fine and high roundness bubbles was investigated.

\section{Experimental Methodology}

\subsection{Specimens Preparation}

Table 1. Chemical composition of AZ31B magnesium alloy.

\begin{tabular}{lllllllll}
\hline Elements & $\mathbf{A l}$ & $\mathbf{Z n}$ & $\mathbf{M n}$ & $\mathbf{S i}$ & $\mathbf{F e}$ & $\mathbf{C u}$ & $\mathbf{N i}$ & $\mathbf{M g}$ \\
\hline Composition (wt.\%) & 2.7852 & 0.7925 & 0.5635 & 0.0032 & 0.0002 & 0.0003 & 0.0004 & Bal. \\
\hline
\end{tabular}

AZ31B magnesium alloy (with its compositions shown in Table 1) was used as the matrix. Hollow ceramic microspheres (CMs, mainly composed of $\mathrm{SiO}_{2}$ and $\mathrm{Al}_{2} \mathrm{O}_{3}$ ) were used as compound addition to fabricate magnesium composite foam. Detailed parameters of CMs were as follows: diameter, stacking density and wall thickness were $45-100 \mu \mathrm{m}, 0.42 \mathrm{~g} / \mathrm{cm}^{3}$ and $7.5 \mu \mathrm{m}$ respectively. To ensure the uniform distribution of $\mathrm{CMs}$, a modified melt foaming method was applied and the detailed steps were as follows: 1) cutting about $1 \mathrm{Kg}$ of AZ31B magnesium alloy cylindrical billet to about $10 \mathrm{~mm}$ sheets and then divide the sheets into isometric by hollow ceramic microspheres (account for magnesium matrix volume fraction $20 \%$ ) layer by layer; 2 ) melting the raw materials in a mild steel crucible at $700^{\circ} \mathrm{C}$ $-710^{\circ} \mathrm{C}$; 3) thickening the melt with different kinds of thickening agents to increase its viscosity and the detailed description is shown in Table 2; 4) thickening temperature was approximately $690^{\circ} \mathrm{C}$ with stirring paddle stirring rate and mixing time were 500rpm and 8 minutes, respectively; 5) adding about $2.0 \mathrm{wt} . \% \mathrm{CaCO}_{3}$ powder (analytically pure) into the melt with stirring speed of $1000 \mathrm{rpm}$ for 25 seconds; 6) keeping the crucible in the resistance furnace for $40-50$ seconds and then removing the crucible out to make it cool to room temperature. During the whole process $\mathrm{SF}_{6}$ and $\mathrm{CO}_{2}$ gas mixture was used to prevent the melt from being ignited or oxidized.

Table 2. Composite foam with different thickening agents and porosity.

\begin{tabular}{lllll}
\hline Composite foam & A & B & C & D \\
\hline Thickening agent & none & 1 wt. $\% \mathrm{Mg}-30 \mathrm{Ce}$ & $0.3 \mathrm{wt} . \% \mathrm{Ca}$ & $0.3 \mathrm{wt} . \% \mathrm{Ca}$ and $1 \mathrm{wt} . \% \mathrm{Mg}-30 \mathrm{Ce}$ \\
Porosity (\%) & 25 & 45 & 75 & 60 \\
\hline
\end{tabular}

It should be noted that the preparation process and parameters for contrast experiments were exactly same except for the types of thickening agents.

\subsection{Microstructure Observation}

Specimens for microstructure observation were prepared by standard metallographic procedures including polishing with different diamond pastes without contacting with water. Microstructure examinations were performed on optical microscopy (OM, Axio Vert. A1) and field-emission scanning electron microscopy (SEM, JSM-IT500) with energy dispersive X-ray spectrometer (EDS). Phase composition was analyzed by X-ray diffraction (XRD, Smart Lab, Rigaku) using a Brucker D8 Abvence diffractometer. $\mathrm{Cu}_{\mathrm{K} \alpha} \mathrm{X}$-ray radiation was used with an angular step equal to $0.02^{\circ}$. Peaks from particular phases were identified according to ICDD PDF-4+ cards. During analyzing the statistics data about pore size and roundness of pores, Image-Pro Plus software was used.

\section{Results and Discussion}

\subsection{Mathematical Model of Pore Roundness}

Pores roundness is an important factor to evaluate the mechanical properties of magnesium composite foam. In this paper, simple mathematical models and expressions are established to calculate the grade of pores roundness of metal foams. In order to do this, some preparations and assumptions need to be done, i.e.: 

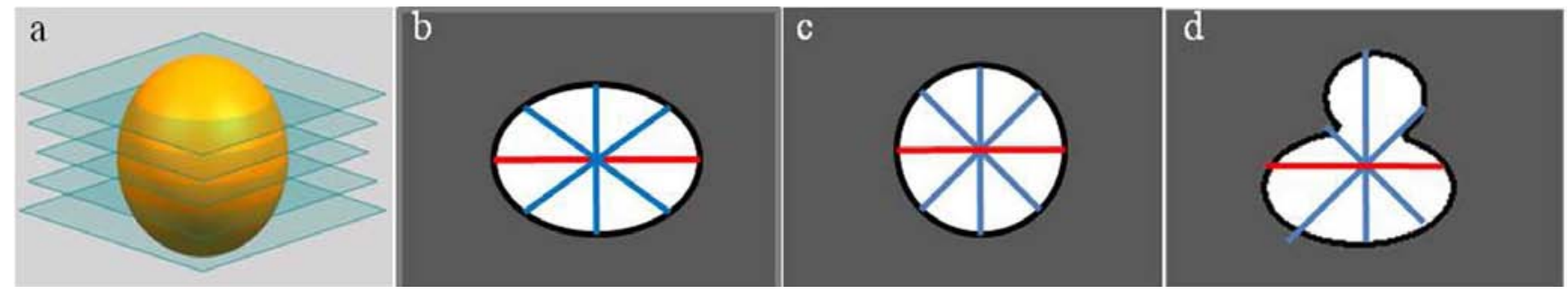

Figure 1. Average length of diameters measured at 2 degree intervals and passing through object's centroid.

At first, we all know that pores in the magnesium composite foam are near spherical and the closed-cell magnesium composite foam has dependent pores in the magnesium matrix $[18,19]$. In the cross section of the specimen, it will cross different positions with different pores (it is shown in the (Figure $1 \mathrm{a}$ ), because of the amount of pores are large hence the overall pores outlines in the cross section will approximately represent the overall pores roundness of the specimen. Therefore, we will statistic pores outlines in the cross section to investigate the difference of pores structure in the specimens.
Thus, every pore outline in the cross section can be represented by one of the three models (as shown in (Figure 1 $\mathrm{b}, \mathrm{c}$ and $\mathrm{d}$ ). The pores outline will be measured average length of diameters measured at 2 degree intervals and passing through object's centroid. The level of pore roundness depended on discrepancy of the maximum diameter and minimum diameter of each pore's outline. Based on this, in this work a mathematical model to calculate pore roundness of metal foams was established as follows:

$$
\mathrm{R}=\left(\mathrm{D}_{\max }-\mathrm{D}_{\min }\right) / \mathrm{D}_{\text {mean }} \times 100 \%
$$

Table 3. The degrades of pore roundness.

\begin{tabular}{llllll}
\hline $\mathbf{R}$ & $<\mathbf{3 0} \%$ & $\mathbf{3 0 \% - 5 0 \%}$ & $\mathbf{5 0 \% - 7 0 \%}$ & $\mathbf{7 0 \% - 1 0 0 \%}$ & $>\mathbf{1 0 0 \%}$ \\
\hline Degrade of roundness & I & II & III & IV & V \\
\hline
\end{tabular}

Where $\mathrm{R}$ represents pore roundness, $\mathrm{D}_{\text {mean }}$ means mean diameter of each dependent pore, $D_{\max }$ and $D_{\min }$ mean maximum and minimum diameters of each dependent pore. Five levels (as shown in Table 3) were used to represent the degree of pore roundness, lower level means higher degree of pore roundness and closer to perfect circle [20]. Here we set I
II III IV $\mathrm{V}$ five grades to represent the roundness degree basing on the range of $\mathrm{R}$, the details are shown in the Table 3 . When the roundness degrade is I, it represents that the pore is close to globular. With the roundness grade upgrading, the morphology of pore will gradually deviate globular.

\subsection{Macrostructures of Magnesium Composite Foams with Different Thickening Agents}
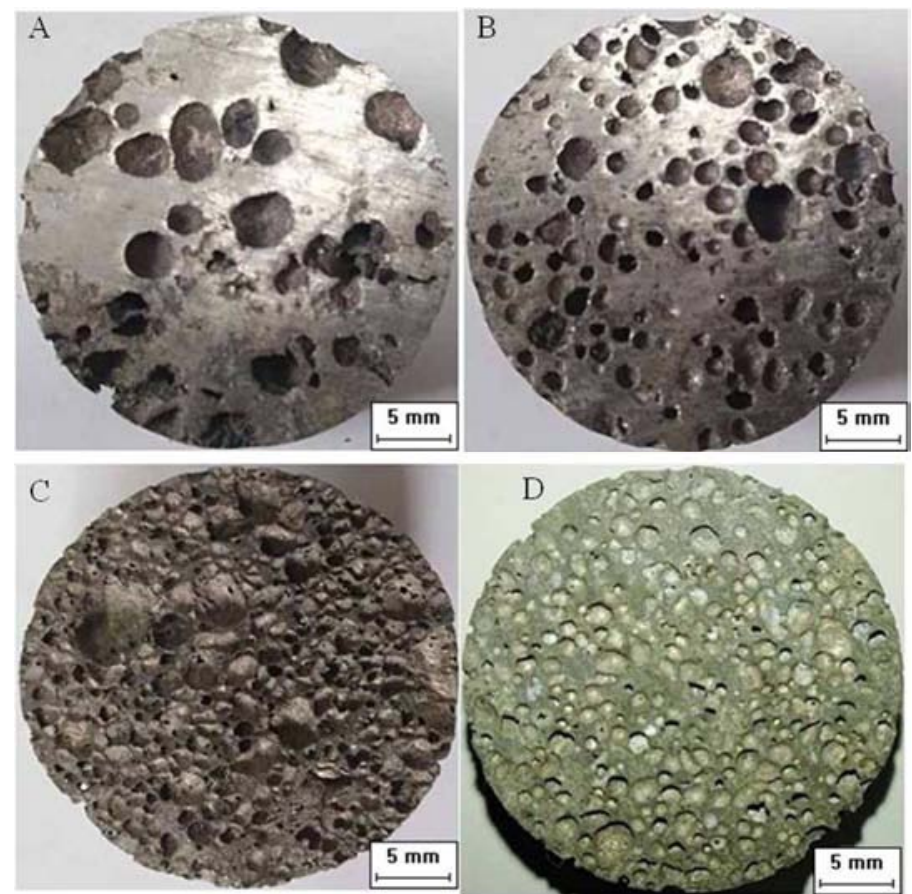

Figure 2. Macrostructures of AZ31B composite foams with different thickening agents, $A$ without thickening agent, $B$ with Mg-30Ce, $C$ with calcium granules, $D$ with both calcium granules and $\mathrm{Mg}$-30Ce. 
Macrostructures of magnesium composite foams with different thickening agents were shown in (Figure $2 \mathrm{~A}, \mathrm{~B}, \mathrm{C}$ and $\mathrm{D}$, respectively. It is clear that thickening agent has significant influence on the final foaming effect of AZ31B/HCMs composite foams. Specimens for macrostructure analysis were cut into cylinder with diameter of $30 \mathrm{~mm}$. we will describe the macrostructure in the following aspects i.e.: firstly, the overall mean diameter of pores; secondly, the range of the pores diameter of the specimen; thirdly, the pores roundness, porosity and the integrity of the pores wall.

Obviously, Figure 2A shows that, firstly, the distribution of pores is nonuniform and the mean diameter of pores in the specimen is big; Secondly the range of pore diameter is wide, the shape of the pores are irregular with sharp edges and some big cracks exist in the pores wall and the porosity of the specimen is low. Figure $2 \mathrm{~B}$ shows that the level of pore roundness is improved and the outline of pores wall is gentle

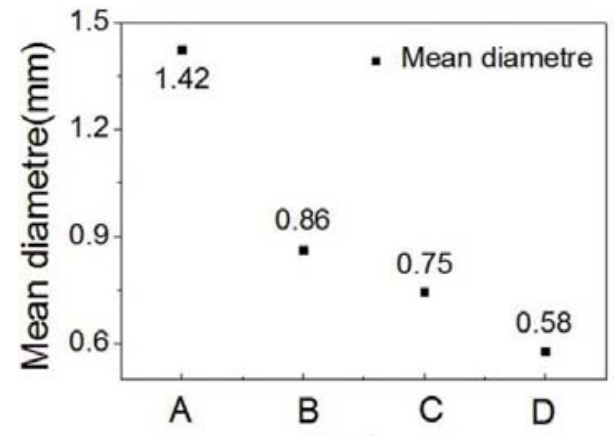

(a) without sharp crack, but the pore distribution is still nonuniform and its porosity is low will large pores distributing in the section, the range of pores diameters is wide. Figure 2C shows that some pores interconnect together because of the incomplete cell walls and obvious difference in pore diameters can be observed in the section. Figure 2D shows uniform distribution of pores with small pore sizes and integrated cell walls, also the pore roundness is obviously improved. All of these mean that composite thickening agents enhance the foaming effect and improve pore roundness of magnesium composite foam. It is known that defects make great influence on overall mechanical character of magnesium composite foams, e.g. large cracks and poor pore roundness in magnesium matrix foam will lead to stress concentration and obvious difference of pore diameters will also result in imbalance of holes edge weight on each cross section. Composite foams with modified spatial macrostructure possess excellent comprehensive characters [21-23].

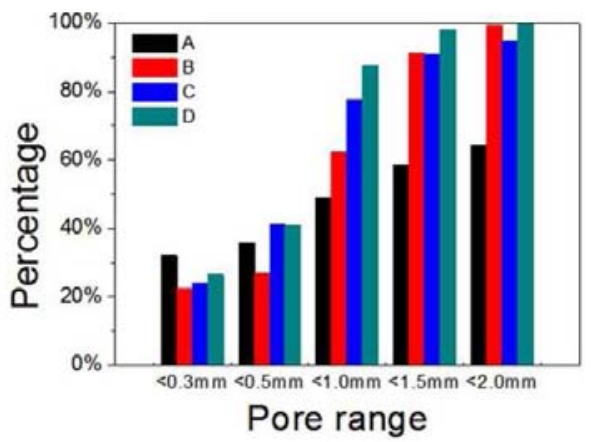

(b)

Figure 3. Mean diameter and distribution range of $A Z 31 B$ composite foam pores for composite foam $A / B / C / D$.

It had been observed that the mean diameter of the pores in the composite foam with composite of calcium granules and $\mathrm{Mg}-30 \mathrm{Ce}$ as composite thickening agent was the smallest of all the specimens as shown in the Figure 3 (a); from the analysis of difference in pores diameter and the diameter distribution range of pores of the composite foam, Figure 3 (b) showed approximately $90 \%$ pore diameter was less than $1 \mathrm{~mm}$, more than $50 \%$ pores diameter was between $0.5 \mathrm{~mm}$ and $0.1 \mathrm{~mm}$ and it showed none for greater than $2 \mathrm{~mm}$, so there was not obvious difference in pores diameter of the composite foam with calcium granules and $\mathrm{Mg}-30 \mathrm{Ce}$ as thickening

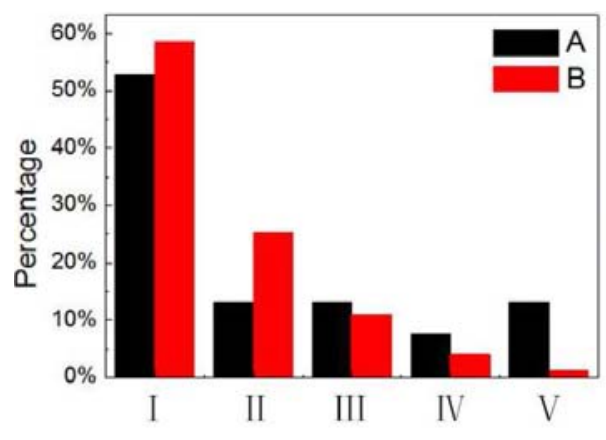

(a) agents. Compared with the other three specimens it was even more uniform and fine in pores diameter.

With calcium granules as one kind of thickening agents, it had an obvious effect on the pore diameter and the porosity of the composite foam, the mean diameter of the pore was reduced to the original half and the porosity of four contrast experiments with different thickenings was shown in the Table 2 , it showed that the calcium granules make an significant effect on the porosity of the composite foam. With the calcium granules adding, the porosity was improved remarkably [24].

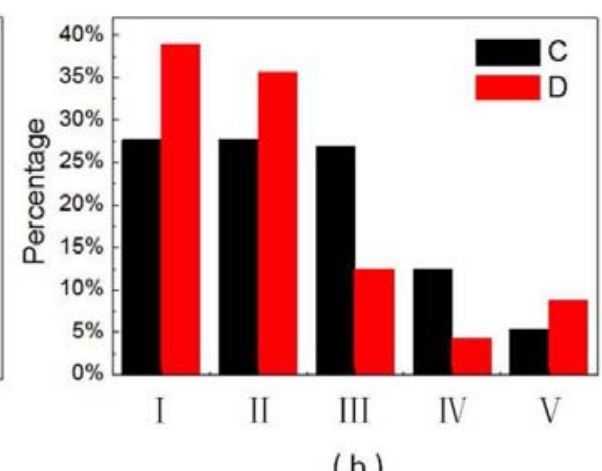

(b)

Figure 4. The distribution grades of pores on cross section of AZ31B composite foam. 
Figure 4 showed that the pores roundness in the cross section of specimens for the two groups of specimens of the contrast experiments $\mathrm{A}$ to $\mathrm{B}$ and $\mathrm{C}$ to $\mathrm{D}$, when $\mathrm{Mg}-30 \mathrm{Ce}$ was existing in the thickening agents, Figure 4 (a) showed that the percentage of pores with high roundness outline in the cross section was higher compared to the thickening agents without $\mathrm{Mg}$-30Ce. The samples were as follows, in the first bar chart of Figure 4 (b), it accounted for nearly $90 \%$ pores in the cross section of specimen for experiment $\mathrm{B}$; Compared to experiment $A$, it was obvious that just nearly $60 \%$ pores in the cross section, when the pores roundness degree were at I - II grade. It meant that the degree of pores roundness of experiment $\mathrm{B}$ is higher than that in the experiment $\mathrm{A}$. In the second bar chart of Figure 4 (b), compared experiment $C$ with
$\mathrm{D}$, it accounts for nearly $80 \%$ pores in the cross section of specimen for experiment $\mathrm{D}$, when the pores roundness degree grade were at I - II, which is lower than $50 \%$ in experiment $\mathrm{C}$, it means the degree of pores roundness of experiment $\mathrm{D}$ is higher than the experiment $\mathrm{C}$. It improved that with the $\mathrm{Mg}-30 \mathrm{Ce}$ in the thickening agents would improve the pores roundness degree, and make the pores close to perisphere.

Fabricating magnesium matrix composite foam with composite thickening agents (calcium granules and $\mathrm{Mg}-30 \mathrm{Ce}$ ) would improve the spatial structure, avoid defects and get fine-round porosity pores, uniform pores diameter, homogeneous distribution of pores and integrate pores wall, which decided the foaming effects and the overall performance of composite foam.

\subsection{The Mechanism Analysis for the Effects of Composite Thickening Agent on Composite Foam Spatial Structure}

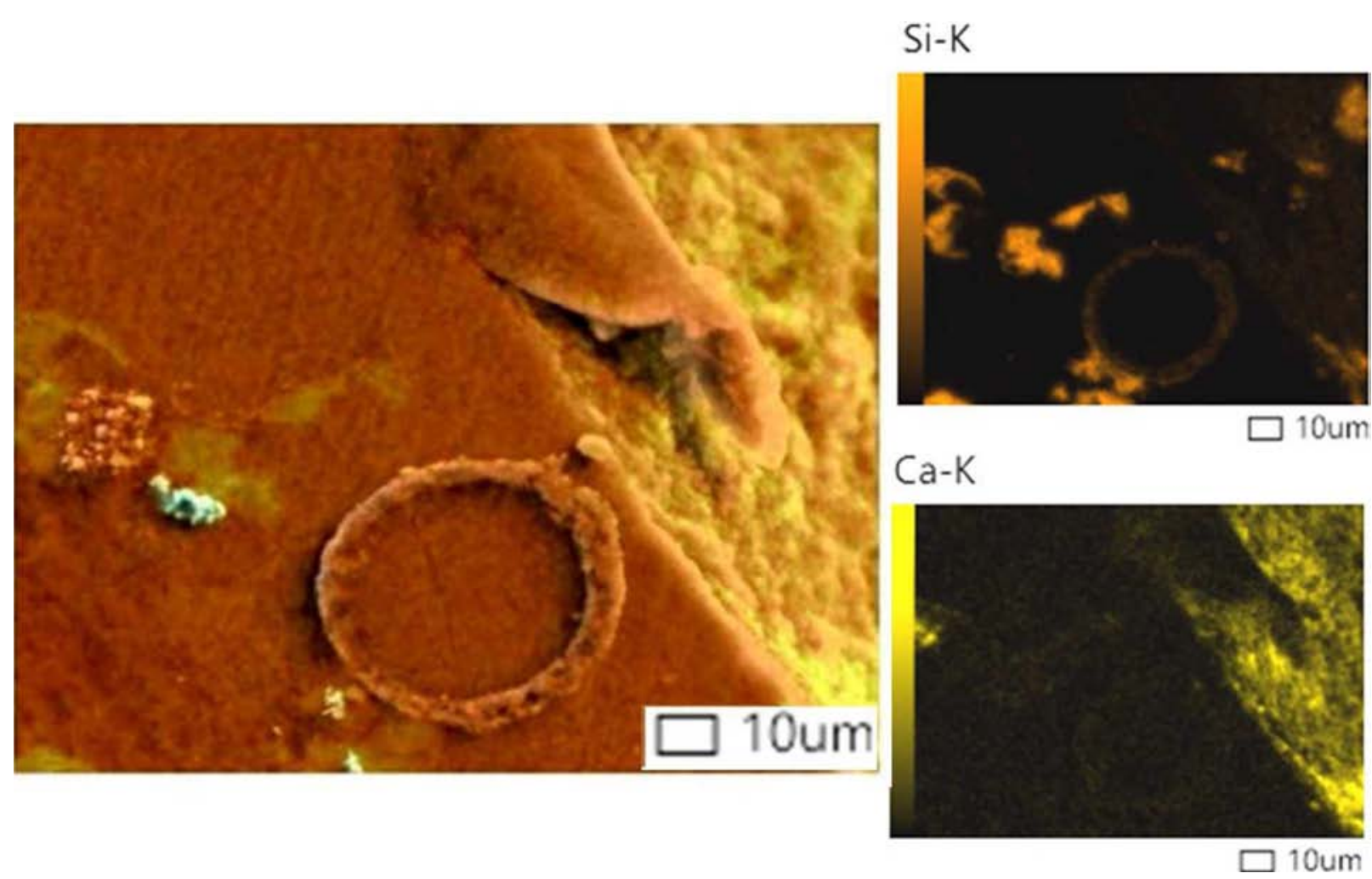

Figure 5. Distribution of Ca and Si elements on cell walls of AZ31B/HCM composite foam with Ca and Mg-30Ce as thickening agent.

Figure 5 Showed the SEM sweep surface images of AZ31B/HCMs composite foam with $\mathrm{Ca}$ and $\mathrm{Mg}-30 \mathrm{Ce}$, it showed one round hole which had obvious metal foam holes' features (furrows or micro crack formed in the cooling stage because of the shrinking percentage difference of the metal matrix and the gas pore) and the distribution of element and particles near the pores wall interface. In the thickening stage, rapidly stirring were for making HCMs and thickening agents distributed homogeneous in the liquid metal. The calcium granules as thickening agent were added to the liquid metal for increasing the liquid viscosity, meanwhile Figure $5 \mathrm{Ca}-\mathrm{K}$ (a surface map of the calcium element) showed that the calcium element was mainly distributed on the cell walls, the enrichment of calcium on the cell wall can make the cells wall more stable during the stirring process, more cells walls were more stable to prevent from being broken, therefore the porosity would be improved with the calcium granules [19, 22, 25]. Figure $5 \mathrm{Si}-\mathrm{K}$ showed the distribution of Si element, the area was the particles position near the interface of cells wall. During the process of synthesis AZ31B magnesium alloy with $\mathrm{HCMs}$ for fabricating composite foam, the $\mathrm{SiO}_{2}$ of $\mathrm{HCMs}$ would produce chemical reaction with magnesium alloy, and $\mathrm{Mg}_{2} \mathrm{Si}$ would be created as the product, when the temperature was high during the casting $[9,10]$. 

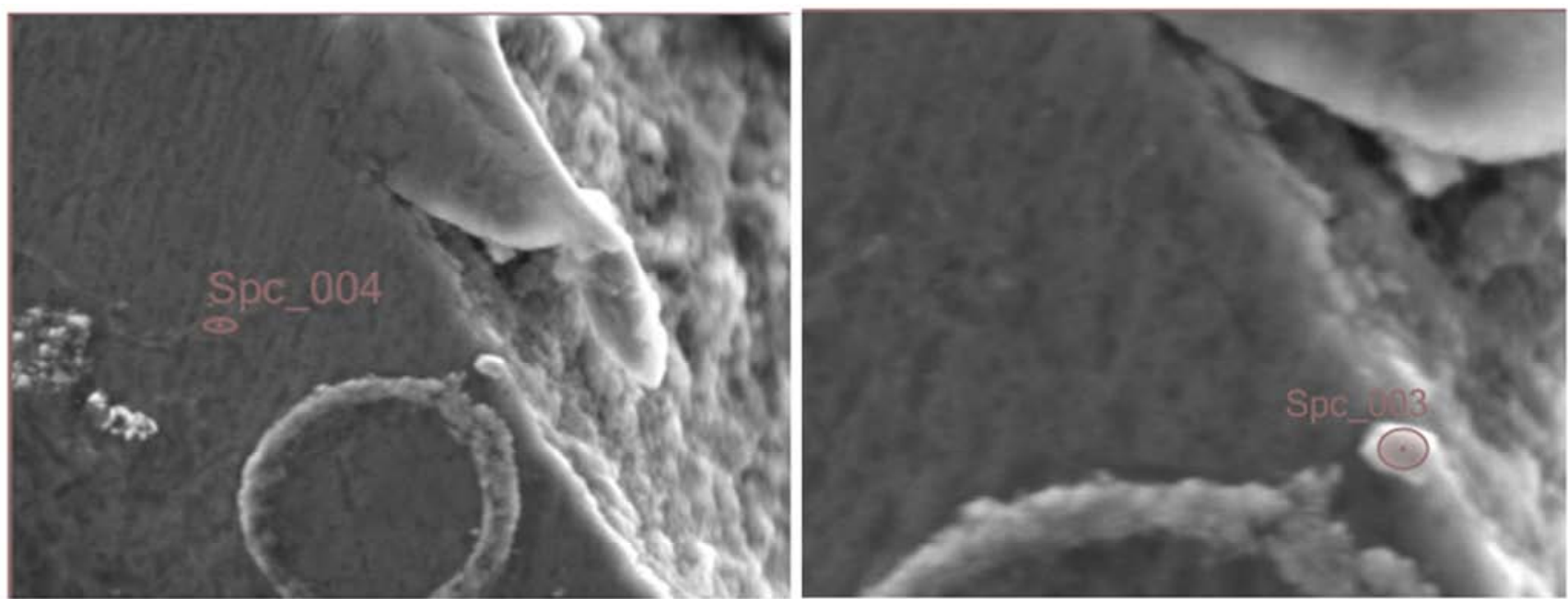

\begin{tabular}{|l|l|r|r|}
\multicolumn{1}{c}{} & \multicolumn{2}{c|}{} & \multicolumn{1}{c|}{$10 \mu \mathrm{Mm}$} \\
\hline \multicolumn{1}{c|}{ Element } & \multicolumn{1}{c|}{ Line } & \multicolumn{1}{c|}{ Mass\% } & \multicolumn{1}{c|}{ Atom\% } \\
\hline $\mathrm{Mg}$ & $\mathrm{K}$ & $77.52 \pm 0.18$ & $79.92 \pm 0.19$ \\
\hline $\mathrm{Al}$ & $\mathrm{K}$ & $2.22 \pm 0.06$ & $2.06 \pm 0.06$ \\
\hline $\mathrm{Ki}$ & $\mathrm{K}$ & $20.02 \pm 0.15$ & $17.87 \pm 0.13$ \\
\hline $\mathrm{Ca}$ & & $0.24 \pm 0.02$ & $0.15 \pm 0.01$ \\
\hline Total & & 100.00 & 100.00 \\
\hline Spc_004 & & & Fitting ratio 0.0477 \\
\hline
\end{tabular}

\begin{tabular}{|c|c|c|c|}
\hline Element & line & Mass\% & Atom\% \\
\hline $\mathrm{Mg}$ & $k$ & $47.32 \pm 0.15$ & $56.97 \pm 0.18$ \\
\hline Al & $k$ & $25.38 \pm 0.15$ & $27.53 \pm 0.16$ \\
\hline Si & K & $1.79 \pm 0.05$ & $1.87 \pm 0.05$ \\
\hline $\mathrm{Ca}$ & K & $0.20 \pm 0.02$ & $0.15 \pm 0.01$ \\
\hline $\mathrm{Mn}$ & K & $25.31 \pm 0.18$ & $13.48 \pm 0.10$ \\
\hline Total & & 100.00 & 100.00 \\
\hline \multicolumn{3}{|l|}{ Spc_003 } & tio 0.0444 \\
\hline
\end{tabular}

Figure 6. Composition of particles on cell walls of AZ31B/HCM composite foam with Ca and Mg-30Ce as thickening agent.

The solid particles near the cell walls in the matrix of magnesium alloy played a vital role on the developing composite foam due to controlling the foaming progress [28]. The particles had been in Figure 6 the composite foam can be evaluated as Mg-Al-Si and Mg-Al-Si-Mn compositions. It had been observed from SEM and XRD analysis. The presence particles near the interface of the cell walls in the composite foam had been illustrated as $\mathrm{Mg}_{2} \mathrm{Si}, \mathrm{Al}_{8} \mathrm{Mn}_{5}$, it was shown in Figure 7 in details. Meanwhile HCMs some were penetrated, others were not penetrated existing near the cell walls.

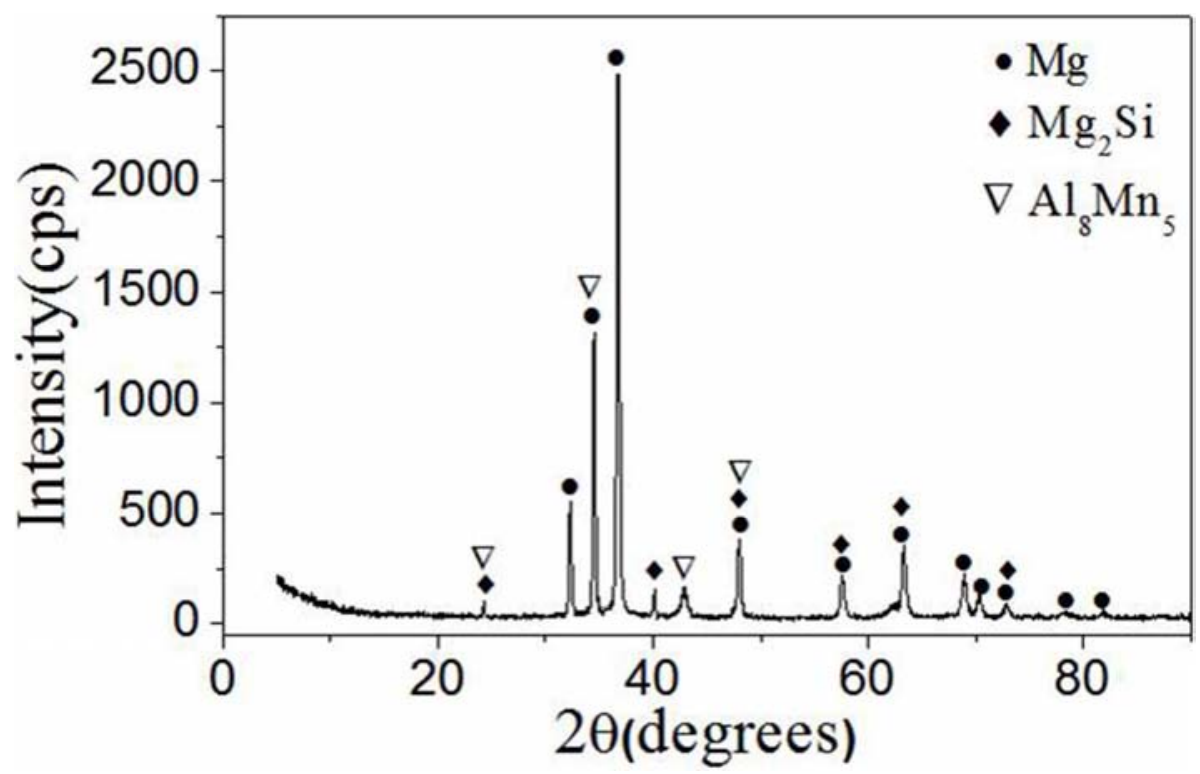

Figure 7. XRD detection results of AZ31B/HCM composite foam with Ca and Mg-30Ce as thickening agent.

Compared the experiments A with $\mathrm{C}$, and the experiments $\mathrm{B}$ with $\mathrm{D}, \mathrm{Mg}-30 \mathrm{Ce}$ was the experiments' variable element of the two groups of experiments. In the images of Figure $8 \mathrm{~A}$ and $\mathrm{B}$, there were many blocky-shaped $\mathrm{Mg}_{2} \mathrm{Si}$ particles existed in the magnesium matrix. In the image of Figure $8 \mathrm{C}$ and $\mathrm{D}$, there were many dendritic $\mathrm{Mg}_{2} \mathrm{Si}$ particles existed in the magnesium matrix. Compared the two groups of images of Figure 8 a, c, A, C and B, D, it was obvious that the number, morphology, size of $\mathrm{Mg}_{2} \mathrm{Si}$ particles had a big shaking-out. The Mg-30Ce had an obvious influence on the product $\left(\mathrm{Mg}_{2} \mathrm{Si}\right)$ of $\mathrm{SiO}_{2}$ and magnesium. The Ce element would enrich in the interface of $\mathrm{Mg}_{2} \mathrm{Si}$ particles, which would make an effect on 
the morphology of the particles, leading to the dendritic structure features, besides Ce would be set as the nucleation particles in the liquid metal for the $\mathrm{Mg}_{2} \mathrm{Si}$ particles, therefore, the numbers of the particles had an obvious increase [26-27].
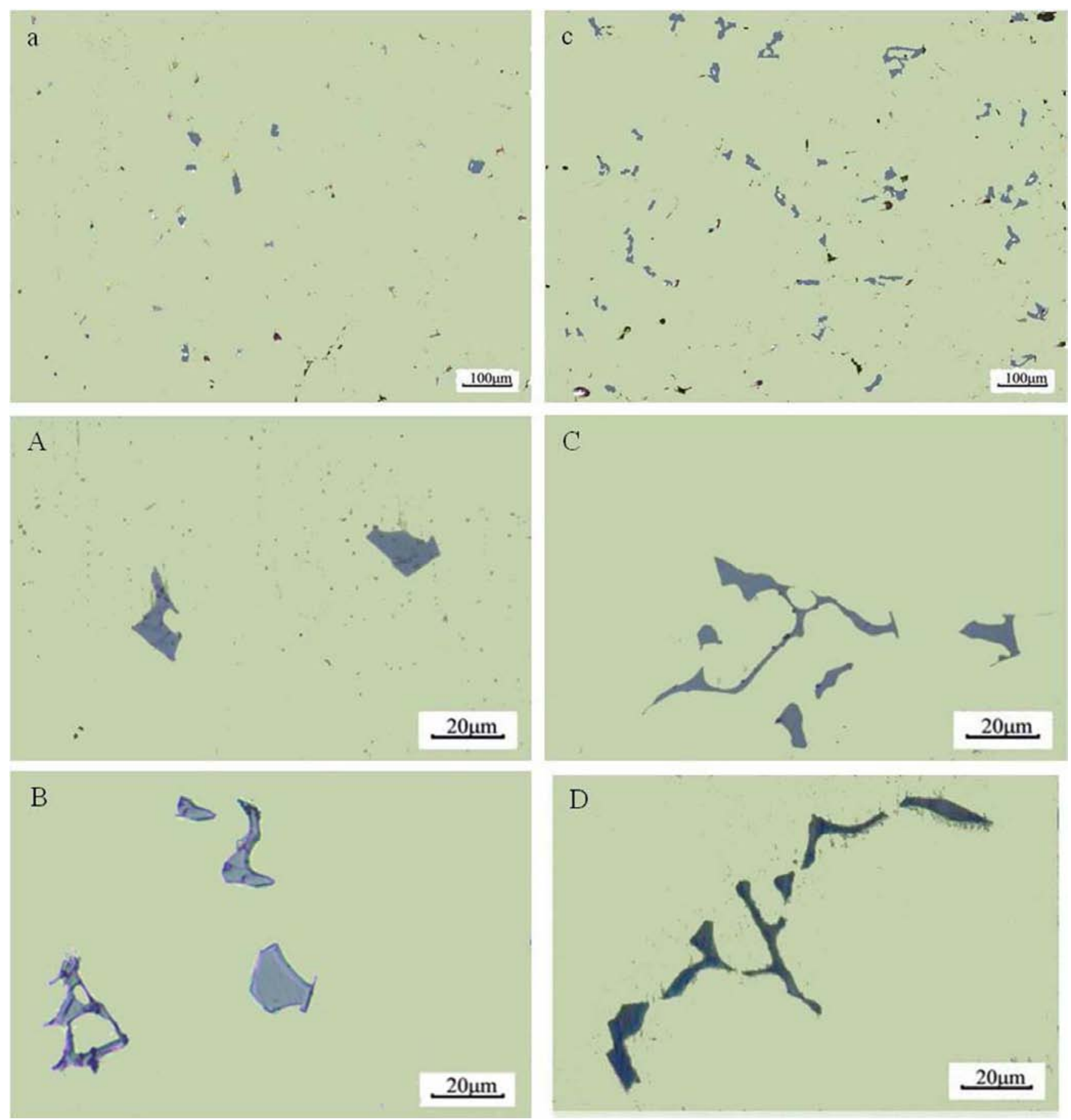

Figure 8. Microstructure of the matrix of AZ31B/HCM composite foam with different thickening agents, A/a without thickening agent, C/c with Mg-30Ce, B with calcium granules, $D$ with both calcium granules and $M g-30 C e$.

\subsection{Influence of Foaming Stage for the Spatial Structure Foaming Process Simu}

Foaming stage was a vital process during fabricating composite foam. After thickening, there were many solid particles which the melting point was higher than the magnesium alloy [28-29]. Figure 9 showed an integrated final bubble of the composite foam, meanwhile showed the cell wall clearly. The apparent of the cell wall was not smoothly, it was obvious that some particles and some furrows were mounted on the cell wall. 


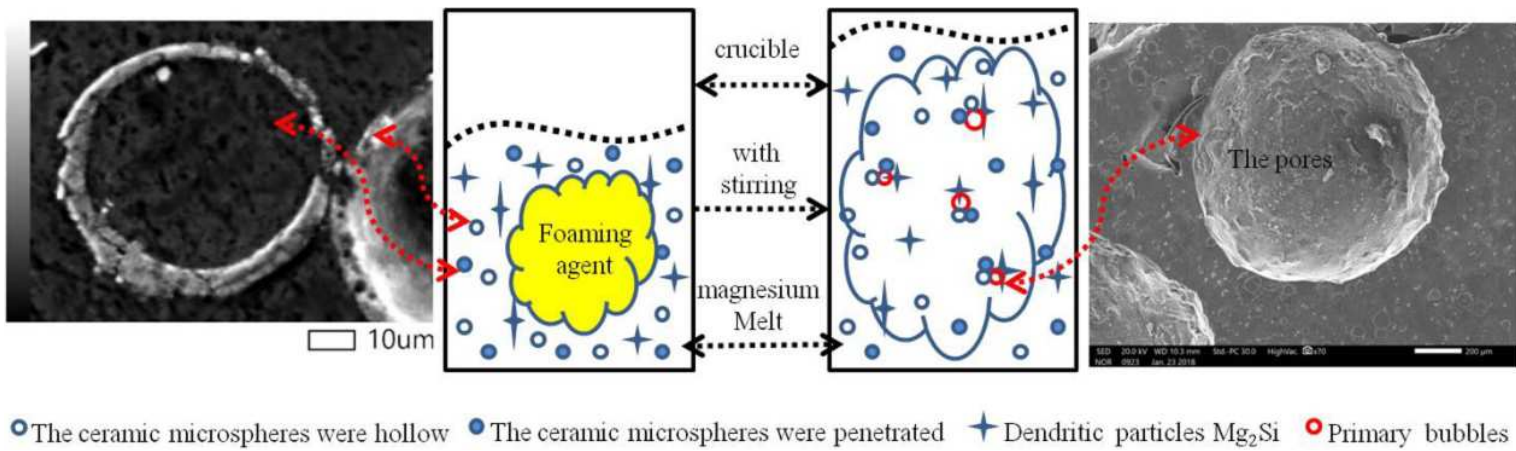

Figure 9. Foaming schematic diagram of AZ31B/HCM composite foam.

Figure 9 showed the foaming model analysis of AZ31B/HCMs composite foam. After thickening stage, the $\mathrm{Mg}_{2} \mathrm{Si}$ particles with dendrite morphology, $\mathrm{HCMs}$ and $\mathrm{Al}_{8} \mathrm{Mn}_{5}$ particles with high-melting-point existed in the liquid metal, after adding the foaming agent, with the impeller stirring quickly, the foaming agent dispersed rapidly. Firstly, the primary bubble will hook on to the solid particles for lower resistance to produce in the liquid metal. Secondly, with the foaming agent decomposed the primary bubbles growed up gradually. At the same time, there were many different particles such as $\mathrm{Mg}_{2} \mathrm{Si}, \mathrm{Al}_{8} \mathrm{Mn}_{5}$ and the $\mathrm{HCMs}$ surrounding near the interface of the primary bubble, which would balance the interfacial tension at any point of the pore for controlling the foaming to get round-shape pores in the composite foam [30-31].

\section{Conclusion}

In the present study, an endeavor had been made to control the spatial structure of the composite foam such as the porosity, the distribution of pores, the range of pore size, the roundness of pore shape, analyzed the influences of the thickening and the foaming process, the following conclusion had been made:

1) With similar modified melt foaming method for fabricating composite foam, different thickenings make a great difference in macrostructure of composite foam.

2) The calcium granules are adding into the melting metal as the thickening, the final foaming effect shows a great improvement in the porosity and pore size of composite foam.

3) $\mathrm{Mg}-30 \mathrm{Ce}$ is added into the melting metal as the thickening, the foaming effect shows a great improvement in the roundness of the composite foam.

4) In the liquid metal, the $\mathrm{Mg}_{2} \mathrm{Si}$ particles morphology, number and distribution is influenced by the thickening $\mathrm{Mg}-30 \mathrm{Ce}$.

5) In the foaming stage, a processing model is set to introduce the primary bubble starting, growing and influencing factors for the roundness of bubbles.

\section{Acknowledgements}

This research did not receive any specific grant from funding agencies in the public, commercial, or not-for-profit sectors. The present authors are also thankful for Dr Lei Wang for microstructure analysis.

\section{References}

[1] J. Banhart, Manufacture, characterisation and application of cellular metals and metal foams, Prog. Mater. Sci. 46 (2001) 559-632. doi: 10.1016/S0079-6425(00)00002-5.

[2] Y. Liao, G. Qiu, Y. Yang, X. Lv, C. Bai, C. University, Preparation and Compressive Properties of Magnesium Foam, Rare Met. Mater. Eng. 45 (2016) 2498-2502.

[3] J. Liu, S. Shi, Z. Zheng, K. Huang, Y. Yan, Characterization and Compressive Properties of $\mathrm{Ni} / \mathrm{Mg}$ Hybrid Foams, Mater. Sci. Eng. A. 708 (2017).

[4] X. Z. Yue, K. Kitazono, X. J. Yue, B. Y. Hur, Effect of fluidity on the manufacturing of open cell magnesium alloy foams, J. Magnes. Alloy. 4 (2016) 1-7.

[5] H. Anantharaman, V. C. Shunmugasamy, O. M. S. Iii, N. Gupta $\mathrm{K}$. Cho, Dynamic properties of silicon carbide hollow particle filled magnesium alloy (AZ91D) matrix syntactic foams, Int. J. Impact Eng. 82 (2015) 14-24.

[6] S. Bhogi, M. Mukherjee, Foam stabilization by magnesium, Mater. Lett. (2017).

[7] K. Heim, G. S. Vinod-Kumar, F. García-Moreno, A. Rack, J. Banhart, Stabilisation of aluminium foams and films by the joint action of dispersed particles and oxide films, Acta Mater. 99 (2015) 313-324.

[8] R. Deleurence, C. Freymond, T. Saison, F. Lequeux, C. Monteux, Foamability and stability of foams obtained with silica/PEI gels, Colloids Surfaces A Physicochem. Eng. Asp. 534 (2017).

[9] K. N. Braszczyńska-Malik, J. Kamieniak, Analysis of interface between components in AZ91 magnesium alloy foam composite with Ni-P coated fly ash cenospheres, J. Alloy. Compd. 720 (2017) 352-359.

[10] K. N. Braszczyńska-Malik, J. Kamieniak, AZ91 magnesium matrix foam composites with fly ash cenospheres fabricated by negative pressure infiltration technique, Mater. Charact. 128 (2017). 
[11] G. Anbuchezhiyan, B. Mohan, D. Sathianarayanan, T. Muthuramalingam, Synthesis and characterization of hollow glass microspheres reinforced magnesium alloy matrix syntactic foam, J. Alloy. Compd. 719 (2017) 125-132.

[12] N. Politova, S. Tcholakova, Z. Valkova, K. Golemanov, N. D. Denkov, Self-regulation of foam volume and bubble size during foaming via shear mixing, Colloids Surfaces A Physicochem. Eng. Asp. 539 (2018) 18-28.

[13] Z. Sun, L. Gao, Effect of Elastic Modulus of Ductile Cast Iron on Graphite Morphology, Hot Work. Technol. 40 (2011) 34-38.

[14] D. Falliano, D. De Domenico, G. Ricciardi, E. Gugliandolo, Experimental investigation on the compressive strength of foamed concrete: Effect of curing conditions, cement type, foaming agent and dry density, Constr. Build. Mater. 165 (2018) 735-749.

[15] A. Aldoshan, S. Khanna, Effect of relative density on the dynamic compressive behavior of carbon nanotube reinforced aluminum foam, Mater. Sci. Eng. A. 689 (2017) 17-24.

[16] B. I. Yu-Shun, X. Q. Zuo, Preparation Method and Application of Porous Foam Metal, Nonferrous Met. Process. (2007).

[17] Wang, Y. M, Zhang, B. C, Zhou, D. H, Yang, X. J, Z. P, Mold-Filling Ability of Aluminum Alloy Melt during the Two-Step Foaming Process, J. Mater. Sci. Technol. 32 (2016) 509-514.

[18] J. Wang, Z. Zhang, Q. Jiang, X. Xia, C. Qiu, J. Ding, W. Zhao, A novel bubble nucleation particle for magnesium composite foam, Mater. Lett. 193 (2017) 187-190.

[19] X. Xia, J. Feng, J. Ding, K. Song, X. Chen, W. Zhao, B. Liao, B Hur, Fabrication and characterization of closed-cell magnesium-based composite foams, Mater. Des. 74 (2015) 3643.

[20] J. Wang, Z. Yin, Z. J. Cao, S. G. Lai, Y. Y. Pei, Evaluation of pellets sphericity using computer assistant image analysis, Chinese Pharm. J. 40 (2005) 529-531.

[21] S. F. Aida, H. Zuhailawati, A. S. Anasyida, The Effect of Space Holder Content and Sintering Temperature of Magnesium Foam on Microstructural and Properties Prepared by Sintering
Dissolution Process (SDP) Using Carbamide Space Holder, Procedia Eng. (2017) 290-297.

[22] X. C. Xia, X. W. Chen, Z. Zhang, X. Chen, W. M. Zhao, B. Liao, B. Hur, Effects of porosity and pore size on the compressive properties of closed-cell $\mathrm{Mg}$ alloy foam, J. Magnes. Alloy. 1 (2013) 330-335.

[23] T. H. Reddy, S. Pal, K. C. Kumar, M. K. Mohan, V. Kokol, Finite Element Analysis for Mechanical Response of Magnesium Foams with Regular Structure Obtained by Powder Metallurgy Method 论, Procedia Eng. 149 (2016) 425-430.

[24] M. Mukherjee, F. García-Moreno, C. Jiménez, A. Rack, J. Banhart, Microporosity in aluminium foams, Acta Mater. (2017).

[25] M. González-Nava, A. Cruz-Ramírez, M. Á. Suarez-Rosales, Thermodynamic analysis of the aluminum alloy foaming process by melt route, J. Manuf. Process. 32 (2018) 77-84.

[26] J. T. Zhang, L. P. Chen, J. Yin, Application of Ce Alloying in Magnesium Alloy, Foundry Technol. (2011).

[27] Q. D. Qin, Y. G. Zhao, W. Zhou, P. J. Cong, Effect of phosphorus on microstructure and growth manner of primary $\mathrm{Mg} 2 \mathrm{Si}$ crystal in $\mathrm{Mg} 2 \mathrm{Si} / \mathrm{Al}$ composite, Mater. Sci. Eng. A. 447 (2007) 186-191.

[28] T. Wübben, S. Odenbach, Stabilisation of liquid metallic foams by solid particles, Colloids Surfaces A Physicochem. Eng. Asp. 266 (2005) 207-213.

[29] G. Kaptay, Interfacial criteria for stabilization of liquid foams by solid particles, Colloids Surfaces A Physicochem. Eng. Asp. 230 (2015) 67-80.

[30] V. Gergely, T. W. Clyne, Drainage in standing liquid metal foams: modelling and experimental observations, Acta Mater. 52 (2004) 3047-3058.

[31] M. Cuaresma, M. Vázquez, J. L. F. Cordero, I. G. Nores, C. Vílchez, Selection of microalgae with potential for cultivation in surfactant-stabilized foam, Algal Res. 31 (2018). 